\title{
INVESTIGATION OF THE SENSE OF COMMUNITY LEVELS: VARIABLES, DIMENSIONS AND SPATIAL ANALYSIS APPROACH
}

\author{
PAKINAM ASHRAF ${ }^{1}$, HANY M. AYAD ${ }^{2} \&$ DINA M. SAADALLAH ${ }^{2}$ \\ ${ }^{1}$ Department of Human Geography, School of Life \& Environmental Sciences, University of Birmingham, UK \\ ${ }^{2}$ Architecture and Urban Planning, Architectural Engineering Department, Faculty of Engineering, \\ Alexandria University, Egypt
}

\begin{abstract}
Neighborhood sense of community is considered both a theory and a value in the community and social psychology. It has been examined significantly in a wide range of research. However, there is a need to investigate the effect of several independent variables on the sense of community-level change. Consequently, this study attempts to advance the relationship between the sense of community and some factors such as the built environment, the historical background, and the socio-economic conditions in three selected neighborhoods. Besides, in this paper, spatial analysis and observation have been done to identify each neighborhood's main features and residents' engagement level through quantitative analysis and GIS analysis. To reach that aim, an updated methodology composed of a mixed method Consisted of a quantitative survey and a qualitative observation of the built environment features by adding a spatial analysis. Appling this updated methodology to four neighborhoods in Alexandria city, Egypt. This will be achieved through in-depth statistical analysis for the four neighborhoods, followed by GIS analysis for two neighborhoods to correlate the quantitative approach with the quantitative spatial analysis approach for the sample. The findings support the notion that there is a strong correlation between the sense of community and the built environment. The results show, a significant correlation with some demographic factors like age, monthly income, and the importance of community attachment and identity on measuring sense of community. Finally, this study highlighted that the public participation practices increase the residents' attachment to the community, which emphasizes the concept of a sense of community responsibility towards their neighborhood.

Keywords: sense of community, built environment, GIS, Alexandria, Egypt, statistical analysis, public participation, citizen's empowerment.
\end{abstract}

\section{INTRODUCTION}

Explaining the meaning of community, its components, and needs is a significant topic to study. Worth mentioned that researchers aiming to develop a definition of the community should consider both people and place. The place is where people live and are affected, and the people might include the total population of any geographic place or one or more distinguishable smaller groups of people. The complexity of community life could be identified through the community cultural assessment as an essential tool in developing welldesigned strategies that meet the needs and interests of the community and its inhabitants and understanding the formal and informal networks people use for communicating. It is crucial to highlight that communities are dynamic and continuously growing as people move in, move out, become more educated, enter new phases of their lives, or face different challenges [1]. Citizens, politicians, and social researchers used the sense of community as a keyword to identify the relationship between people and their built environment's social structure [2].

In a conceptual framework of community psychology, the idea of community and the psychological sense of community are strongly associated with each other. They are also linked to other concepts, such as participation, empowerment, community development, neighboring, social cohesion, community identity, and quality of life [3]. 
Recently, the sense of community is decreasing at the neighborhood level in many researchers' studies in the Global South. This decrease is usually linked with the built environment's quality [4]. Lately, the quality of Alexandria's neighborhoods has decreased. Several factors are proofing that such as noise, air pollution, and the poor quality of the public transportation system [5]. In 2010, the UNDP report stated that Alexandria contains 29 informal areas, which representing about $2.9 \%$ of the informal settlements of Egypt. Also, about 1.4 million persons, representing about $35 \%$ of Alexandria residents, live in these informal areas. In addition, the number of informal buildings has been increasing in the city's neighborhoods [6].

\section{SENSE OF COMMUNITY}

There is a growing understanding of the advantages and significance of the sense of community in the urban environment in the literature. Definitionally, the sense of community has been described in different ways and through several researchers' contributions. The most accepted model of sense of community comes from psychologists David McMillan and David Chavis, who applied factor analysis to clarify the four main elements of sense of community: membership, influence, integration, and fulfilment of needs, and shared emotional connection. Through these elements, they described the sense of community as "a feeling that members have of belonging, a feeling that members matter to one another and to the group, and a shared faith that members' needs will be met through their commitment to be together". They also created the Sense of Community Index (SCI), which became one of the most applied quantitative measures in analyzing the sense of community in the social sciences field [7].

Furthermore, Kim and Kaplan investigated the physical relationship between the sense of community and urban form and generated adequate measures to test the social and physical dimensions of a sense of community. Their aim was mainly to create a multidisciplinary and distinctive approach to a survey instrument that measures the sense of community. Thus, their framework was divided into four main domains as follows: 1 - Community or place attachment, concerns with residents' connections to their community; 2 - Community identity, refers to personal and public identifications with a specific community with its character; 3 - social interactions, is described as a formal and informal social opportunity in which residents participate to the quality of their relationships; 4 -pedestrianism implies that a community is designed for walking and encouraging street side activities [8]. Furthermore, these domains are divided into some subcomponents, and each subcomponent contains some factors which can be applied and examined the physical attributes and social qualities of the selected community [8], [9].

\section{METHODS AND TOOLS}

This study aims to investigate the effect of some determinants (the built environment, the history of the place, and socio-economic conditions) on the sense of community level. Furthermore, it aims to monitor the physical features of the built environment in the selected neighborhoods and how they affect the sense of community. Consequently, the researchers adopted a methodology, integrating a quantitative survey to examine the sense of community index in four neighborhoods (statistical analysis). Using a spatial analysis was then investigated in two neighborhoods: having a high sense of community and having a low sense of community. This is to examine the spatial distribution of open spaces, social activities, educational activities, and main health services to try to interpret the reason behind the high sense of community and low sense of community. 


\subsection{Study context}

The four selected neighborhoods present different socio-economic conditions, historical background, and physical built environment; Kom El Dikka, Kafr Abdo, Sidy Bishr Kibly, and Syouf Kibly. Kom El Dikka is considered one of the oldest neighborhoods in Alexandria, its residents lived in a low economic condition, but they had a huge historical and cultural heritage. It is associated with many distinctive cultural and historical events. Kom el Dikka's significance goes to the presence of Sayed Darwish's home, the most famous Egyptian composer who lived and grew up in the area. Kafr Abdo, a residential neighborhood for wealthier Egyptians, including professionals, and foreigners living in Alexandria, is considered one of the most high-class neighborhoods but suffering from removing some of its ancient historical villas and establishing new buildings which threatening the quality of the place. Sidy Bishr Kibly and Syouf Kibly are two attached neighborhoods; they began to appear from 1950 to 1960 . In this period, Alexandria attracted many immigrants from nearby rural areas either for work or education, so many neighborhoods appeared in this period for this immigration and natural growth of the city. However, they were not with the same quality old Alexandria. They suffer from the low quality of their informal housing and the rail line and are considered low economy neighborhoods - their location and context shown in Fig. 1.

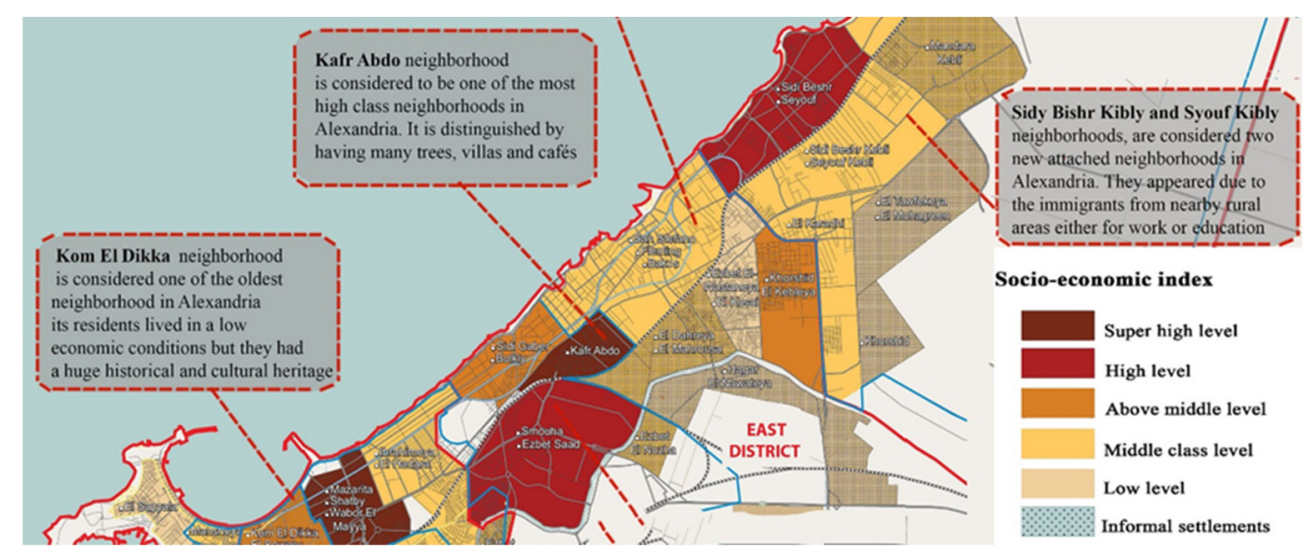

Figure 1: Map shows the administrative boundaries, the social economic conditions, and the location of the three neighborhoods. (Source: Authors.)

\subsection{Sense of community index (statistical analysis)}

The adopted survey (quantitative method) has been used to measure sense of community as a dependent variable. Besides, the statistical analysis aims at analyzing the relation between the dependent variable (sense of community) and the independent variables (built environment, socio-economic conditions, and historical background).

\subsubsection{Measuring the independent variable (sense of community)}

The used survey (sense of community measure) was a composed measure designed based on David McMillan and David Chavis SCI (1986) and Kim and Kaplan theoretical dimensions (2004). 


\subsubsection{Measuring the dependent variables}

The built environment is measured through an observation table of the physical attributes of the built environment. It consists of physical factors suggested by Kim and Kaplan theory, as well as built environment variables (transport, safety and danger, privacy and crowding, participation and empowerment). This observation is divided into three sections Aesthetics, streets and services and buildings. It is a Likert scale tool (bad or not exist $=1$, fair $=2$, good $=3$ ). Besides, the social economic conditions and the history of the neighborhood have been identified using quantitative data and maps and used in the selection of the case studies.

\subsubsection{Sample and data collection}

A random sample of 218 participants from the three neighborhoods was selected based on the Launch Epi Info 7 software. The online survey used the Kwik Survey application. It was shared through different websites such as Facebook, Twitter, and LinkedIn. It has been shared in Arabic and English and targeted different places and people in the selected neighborhoods. The sample included in the final analysis was a total of 218, Kafr Abdo 51, Kom El Dikka 21, and Sidy Bishr and El Seyouf Kibly 146. The survey consisted of 30 questions and divided into three major sections as follow.

Section 1: General personal information

It includes a question regarding gender, age, children's presence, ownership status, level of education, employment status, income, and length of residence. The objective of this part is to know the influence of demographic factors on the respondent's sense of community to know their different ways of thinking.

Section 2: Evaluation sense of community

It is divided into three parts, including the people's opinion about their social interaction within the community, their community attachment and identity, and their community' physical factors (Pedestrian). The responses' answers are in the form of a Likert scale (the five Likert scale varies from 1 to 5 , as $1=$ strongly disagree, to $5=$ strongly agree. This part's targeted objective is concluding the values of sense of community in different neighborhoods and comparing their results to know the impact of cultural factors, social spatial character, physical factors, and their relationship with neighbors on the sense of community.

Section 3: General comments

It includes general comments and thoughts of the survey's respondents. The objective of this part is to conclude recommendations about sense of community. Also, identify the needs of residents towards their community in order to increase its sense of community.

\subsubsection{Survey and built environment observation results}

The data were analyzed using SPSS version 18. First, a descriptive analysis of survey results has been done to identify the percentage of sense of community in each neighborhood. A General Linear Model (GLM) - multivariate analysis - has been used to examine the association between sense of community and social-economic conditions, history of the neighborhood, and the built environment (physical attributes). This approach was adopted according to [10]. Subsequently, the researchers identified the positive or negative relations between the physical observation and the survey result. Finally, a descriptive analysis of significant variables - resulting from the multivariate analysis - has been done to give more detailed results.

The validity and reliability of the survey have been checked and the measure was found to have excellent internal consistency with a Cronbach's alpha of 0.843 . Then, the correlation and internal cohesion between items of the survey has been calculated for a sample of 40 (about $20 \%$ of all the sample). 
The survey results illustrated that the sense of community in Kafr Abdo is moderate to low (the highest SOC), but it is low to moderate in Kom El Dikka and Sidy Bishr and El Seyouf Kibly. Concerning sense of community domains, community attachment and identity is the most effective in measuring sense of community, then Social interaction, and finally pedestrian. The domain of community attachment and identity is moderate to low in Kafr Abdo, low to moderate in Sidy Bishr and El Seyouf Kibly, and in the case of Kom El Dikka, the result is somehow strange the percentage of high equal the percentage of low community attachment and identity. The social interaction is low to moderate in the three neighborhoods.

The pedestrian is moderate to low in Kafr Abdo and Kom El Dikka, but it is low to moderate in Sidy Bishr and El Seyouf Kibly. As shown in Fig. 2.

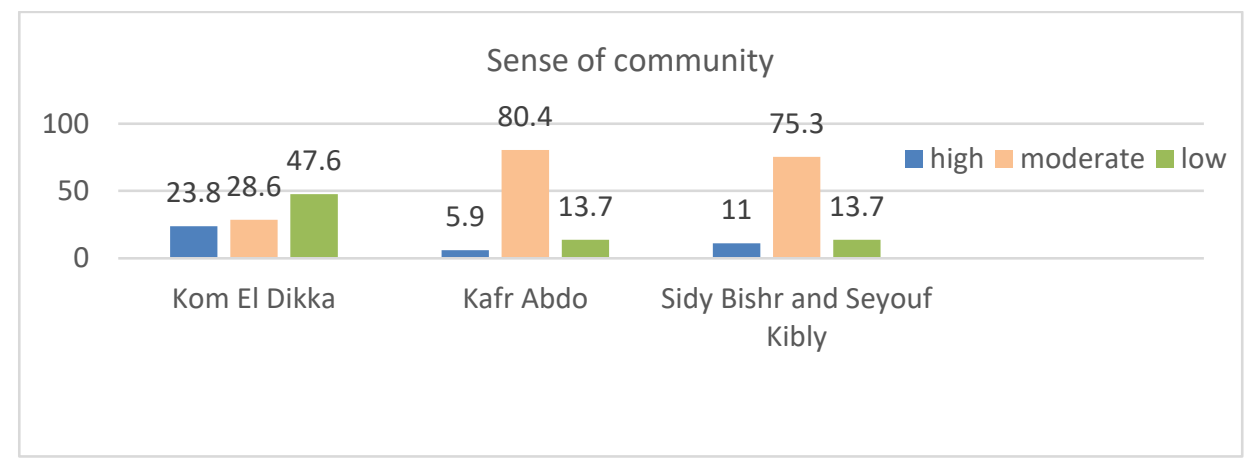

Figure 2: Charts identify the percentage of sense of community in each neighborhood. (Source: Authors.)

The built environment is measured through an observation table of the physical attributes of the built environment. This observation is divided into three sections: Aesthetics, streets and services, and buildings. Each factor has been evaluated, then the total of the section and finally the total of the three sections. The quality of the built environment in each neighborhood in descending order is Kafr Abdo 89\%, Kom El Dikka 75\%, and Sidy Bishr and El Seyouf Kibly 47\%. The built environment in Kafr Abdo is high $(68 \%)$ to moderate $(32 \%)$. Nowadays, the neighborhood suffers from the removal of historical villas and the construction of new buildings with different styles that are not well connected to the past. Kom El Dikka is moderate (59\%) to high (37\%). This neighborhood's problems are mainly included in the maintenance of buildings, respect of buildings lines and proportions. Nowadays, the residents in this neighborhood started a development project to make their neighborhood a better place and applied the concept of public participation. Sidy Bishr and El Seyouf Kibly is low $(68.5 \%)$ to moderate $(21 \%)$. Their problems are almost common the decrease of aesthetics pleasantness, harmony, walkable streets, continuity in buildings. The presence of cars crowding, a huge number of informal buildings with no respect for human scale, and the maintenance of streets and services. Furthermore, a correlation has been done to examine the significance of physical attributes. The physical attributes that are insignificant are the presence of local and unique characteristics, mixed-use neighborhoods, community services, and affordable housing.

In addition, the researchers studied the relationship between physical attributes and the level of sense of community. The scatter chart, in the case of high sense of community in each neighborhood, illustrates a direct correlation (positive relation) between SOC and 
quality of physical attributes. In the case of low sense of community in each neighborhood, an inverse correlation has been illustrated. That means positive relationship between SOC and the quality of physical attributes (built environment). It should be noted that the slop of forecasting line (Y2-Y1/X2-X1) is not the same in the two cases; in the case of high SOC the slop is 0.84 but in the second case the slope is 0.42 . So, the first relationship is more effective. As shown in Fig. 3.

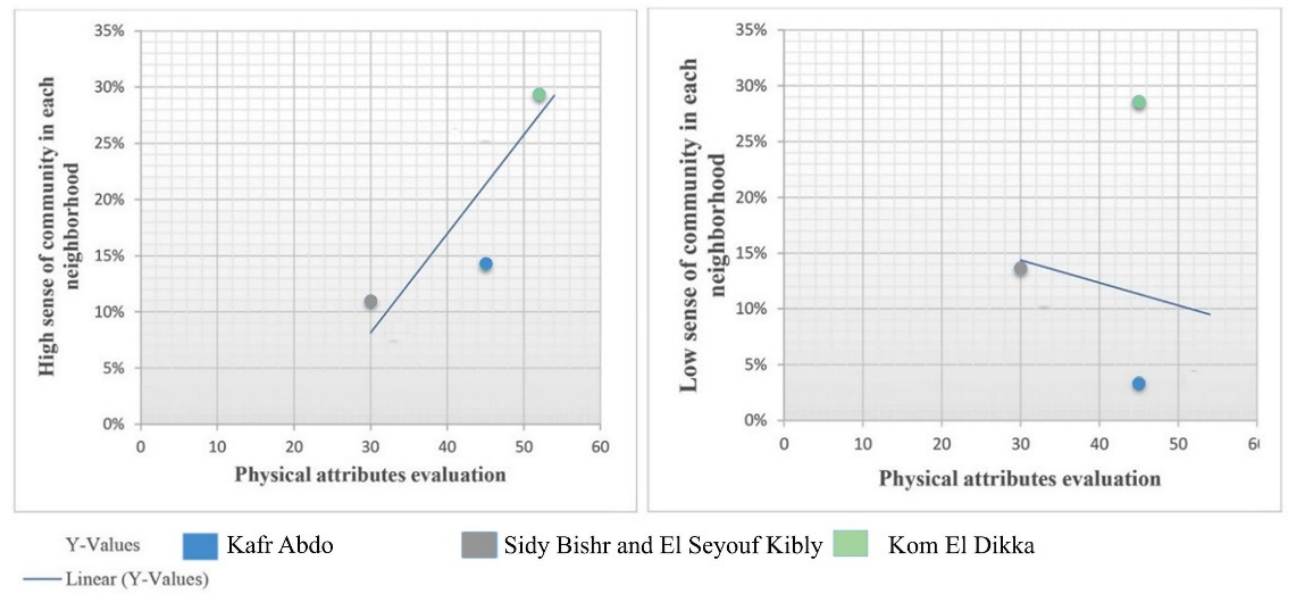

Figure 3: Scatter charts identify the relation between high SOC and physical attributes, Low SOC and physical attributes. (Source: Authors.)

Furthermore, multivariate analysis has been done to test the relationship between the sense of community and all the various independent variables. This accomplished through using a series of four models, each model adjusting for additional variables and mutually adjusting for all other variables in the respective model. The final model (model 4) presents a significance only for the monthly income, the age, and the built environment. As shown in Table 1.

\subsection{Spatial analysis: tools for community mapping}

In the previous part, Demographic variables included gender, age, marital status, socioeconomic status were examined, followed by correlating the sense of community to the physical attribute of built environment. Therefore, it will be followed by a Spatial analysis in order to investigate the relationship between Public Open Space (POS), Community and sports club, nursery, schools, shops and sense of community in residents of two selected neighborhoods, Kafr Abdo and Kom el Dikka, one having high sense of community and the other one has low sense of community. In addition, the Two chosen Neighborhoods exhibit different socioeconomic conditions, and physical built environment: Kafr Abdo and Kom El Dikka, but both neighborhoods are old. Kafr Abdo is considered as a high socio-economic residential neighborhood, the area has been developed between 1900 and 1930. Kom El Dikka is the oldest neighborhood at heart of the central business district of Alexandria, the area is established between 1800 and 1900, low socio-economic one but rich in historical and cultural heritage. This spatial analysis is examining the sense of community exhaustive 
Table 1: Multivariate analysis linear regression models. (Source: Authors.)

\begin{tabular}{|c|c|c|c|c|c|c|c|c|}
\hline & \multicolumn{2}{|c|}{ Model 1 } & \multicolumn{2}{|c|}{ Model 2} & \multicolumn{2}{|c|}{ Model 3} & \multicolumn{2}{|c|}{ Model 4} \\
\hline & $\boldsymbol{\beta}$ & p Value & $\boldsymbol{\beta}$ & p Value & $\boldsymbol{\beta}$ & $\begin{array}{c}\mathbf{p} \\
\text { Value }\end{array}$ & $\beta$ & $\begin{array}{c}\mathbf{p} \\
\text { Value }\end{array}$ \\
\hline Age & -0.354 & $<0.001^{*}$ & -0.308 & $0.001 *$ & -0.300 & $0.001 *$ & -0.297 & $0.001^{*}$ \\
\hline Have children & -0.128 & 0.142 & -0.113 & 0.185 & -0.119 & 0.168 & -0.116 & 0.175 \\
\hline Your current residence & 0.035 & 0.617 & 0.054 & 0.434 & 0.044 & 0.524 & 0.048 & 0.486 \\
\hline Level of education & 0.087 & 0.249 & 0.048 & 0.519 & 0.085 & 0.251 & 0.074 & 0.319 \\
\hline $\begin{array}{l}\text { Current employment } \\
\text { status }\end{array}$ & 0.046 & 0.556 & 0.052 & 0.490 & 0.040 & 0.604 & 0.043 & 0.573 \\
\hline Monthly income & 0.179 & $0.011^{*}$ & 0.158 & $0.022 *$ & 0.182 & $0.009^{*}$ & 0.175 & 0.011* \\
\hline $\begin{array}{l}\text { How long have you } \\
\text { lived in your current } \\
\text { residence }\end{array}$ & -0.473 & 0.637 & -0.050 & 0.504 & -0.042 & 0.574 & -0.045 & 0.546 \\
\hline $\begin{array}{l}\text { Previously moved } \\
\text { from another } \\
\text { neighborhood }\end{array}$ & 0.595 & 0.553 & 0.019 & 0.799 & 0.017 & 0.827 & 0.014 & 0.850 \\
\hline Economy & - & - & 0.225 & $0.001 *$ & - & - & - & - \\
\hline $\begin{array}{l}\text { History of } \\
\text { neighborhood }\end{array}$ & - & - & - & - & -0.189 & $0.009 *$ & - & - \\
\hline $\begin{array}{l}\text { Built environment } \\
\text { observation }\end{array}$ & - & - & - & - & - & - & 0.210 & $0.003 *$ \\
\hline $\mathrm{R}^{2}$ & 0.127 & 0.173 & 0.159 & 0.126 & & & & \\
\hline $\mathrm{F}$ & $3.376^{*}$ & $4.314^{*}$ & 3.883* & $4.111 *$ & & & & \\
\hline $\mathrm{P}$ & $0.001^{*}$ & $<0.001^{*}$ & $<0.001^{*}$ & $<0.001^{*}$ & & & & \\
\hline
\end{tabular}

measure focusing on people-place relationship [11]. Identifying and creating the conditions that foster and strengthen sense of community within residential neighbourhoods in terms of the built environment. According to previous researcher a stronger sense of community has been associated with Public spaces, such as parks and piazzas, are another element of the built environment that may foster sense of community by facilitating chance encounters between neighbours [12]. Less surface parking areas, as high vehicular traffic and car parking negatively affected perceptions of helpfulness and area friendliness and safety [13]. Higher levels of commercial floor space to land area ratios, lower levels of land use mix [10], [14]. Finally, living in neighbourhoods perceived as safe and interesting [12]. Therefore, spatial analysis was applied using. Geographic Information Systems (GIS) to obtain POS size, the number of open spaces within participant's neighbourhood, whether it is public parks, or private garden or major sports and social complex, analysing the percentage of nonresidential which will include educational services, religious, utility buildings, administrative and commercial building to the percentage of residential units, and the network distances from center of neighborhood and the previously mentioned. 'Neighbourhood' was defined as a 5, 10, 15, 20 min walk from the center of neighborhood. Accordingly, a road network buffer $400 \mathrm{~m}, 800 \mathrm{~m}, 1200 \mathrm{~m}$ and $1600 \mathrm{~m}$ was used to capture the neighbourhood within a 10 to 20 min walk [15].

\subsubsection{Data collection}

All the Geospatial data used is collected by the central agency for Public Mobilization and statistics (CAPMAS) and General Organization for physical planning (GOPP). 
As shown in Fig. 4(a)-(c), In Kafr Abdo neighborhood, it is obvious from the spatial analysis that the neighborhood is easy to access within walking distance, and the neighborhood has a variety of open spaces, public open spaces, and private gardens, especially with $1 / 4$ mile walking distance. Within a radius of $1 / 4$ mile, there are educational facilities (nurseries, schools), Religious Facilities (mosque and churches), Administrative facilities (bank, companies), commercial facilities (shops), and utilities (police stations). In addition to the residential use, this means that the residents' basic needs are fulfilled within walking distance; also, according to the questionnaire, the results of the domain of pedestrian in Kafr Abdo were moderate (66.7\%) to high (29.4\%). Also, Kafr Abdo has an $89 \%$ in the researchers' observation of the neighborhood's physical attributes. The evaluation of the streets and services section includes the assessment of some significant points such as mixed mixed-uses, community services, local public parking and transportation, Walkable streets

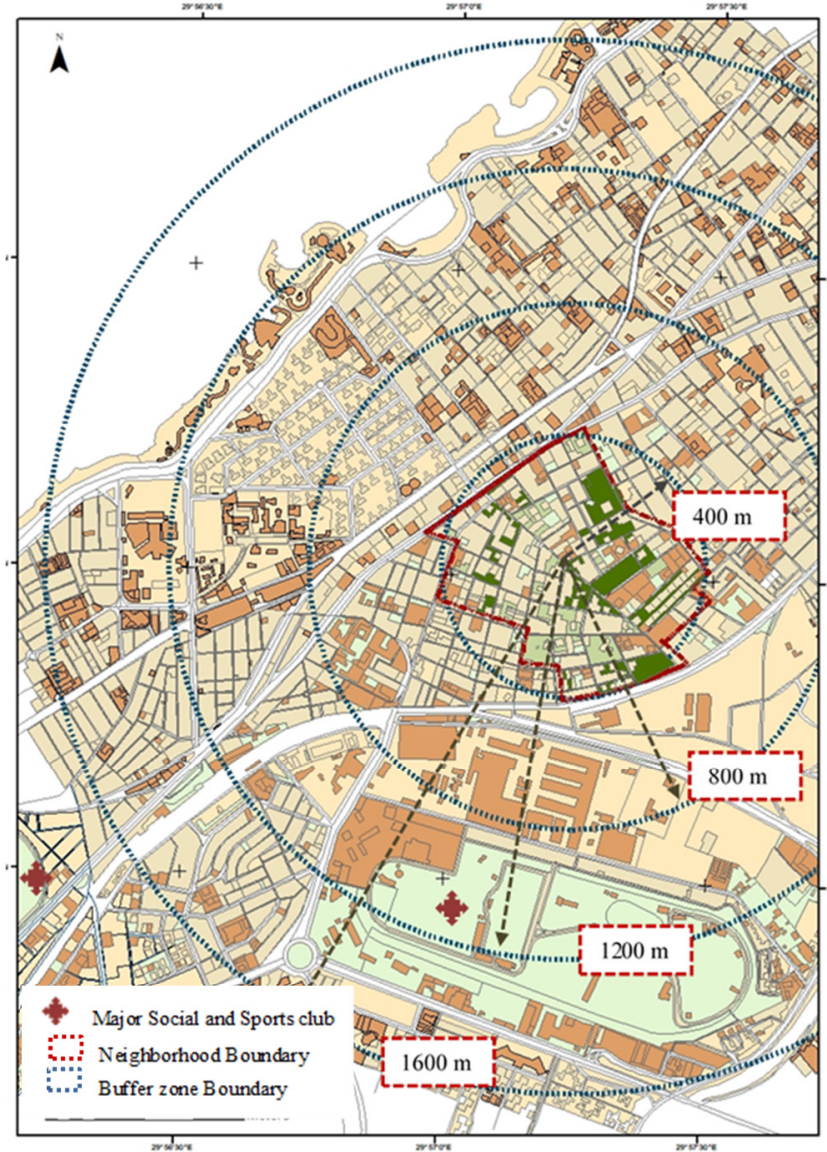

(a)

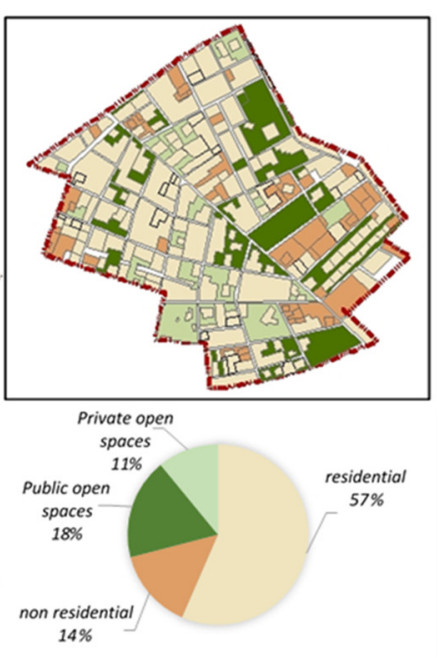

(b)

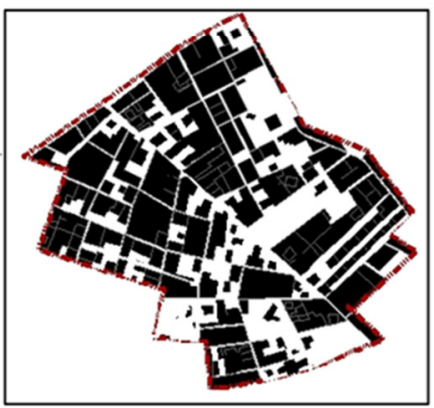

(c)

Figure 4: (a) Representing spatial analysis for Kafr Abdo neighborhood and surrounding context, with in the following radius 400, 800 and $1600 \mathrm{~m}$; (b) Representing percentages of land use; and (c) Representing built up area to open spaces within boundary of Kafr Abdo neighborhood. 
with good sign system which encourage pedestrian activities such as street vendors, and the presence of squares, parks, services, shops, recreation facilities and play areas in their right place. That also exists within $1 / 2$ mile radius, and with $3 / 4$ mile, the residents can reach major sports and social complexes in Alexandria. The spatial analysis shows that the open spaces represent $29 \%$ of the total area of neighborhood, which is considered adequate, and it was mentioned clearly in Section 3 of the survey (participants' comments). They stated that their neighborhood is characterized by open spaces and greenery, which give uniqueness, and that is why they are not satisfied by any change or transformation in their neighborhood. So, now, the percentage of built-up to open spaces is almost $70 \%$ to $30 \%$, which is considered a moderate percentage.

While as shown in Fig. 5(a)-(c), in Kom El Dikka neighborhood, it is obvious from the spatial analysis that the neighborhood is easy to access within walking distance, with in the radius of $1 / 4$ mile there are educational facilities (nurseries, schools) Religious Facilities

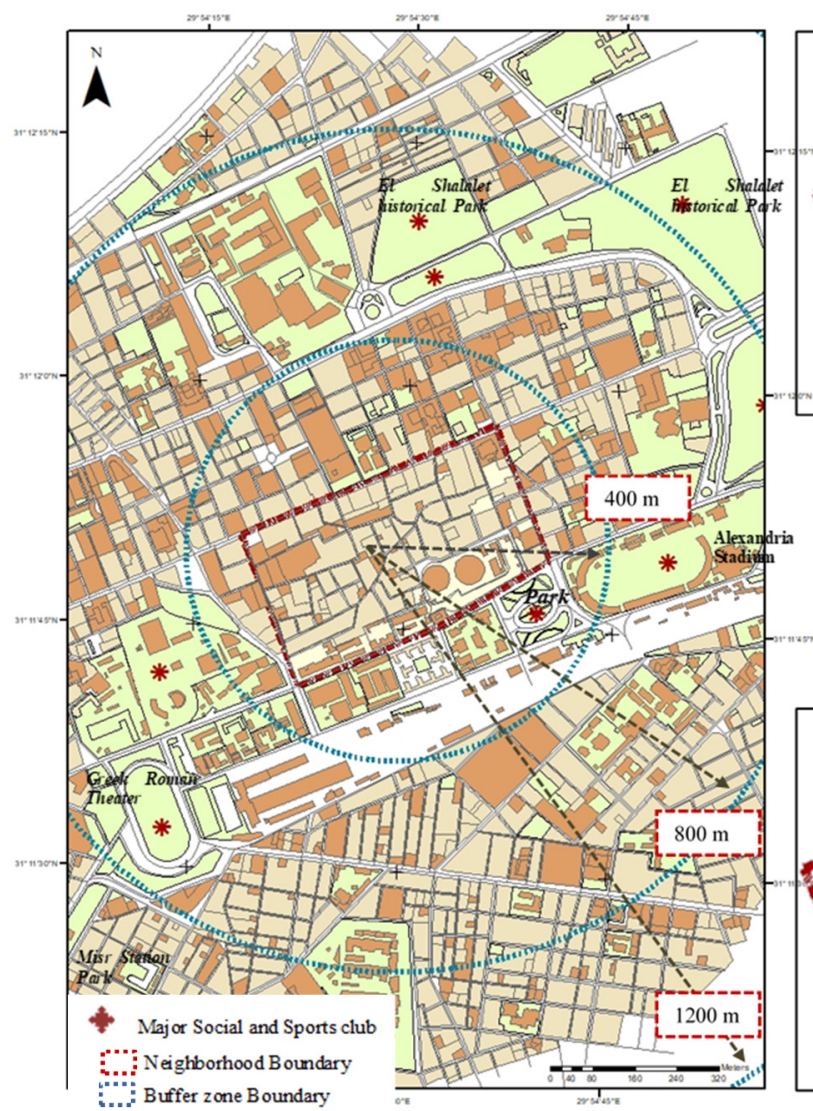

(a)
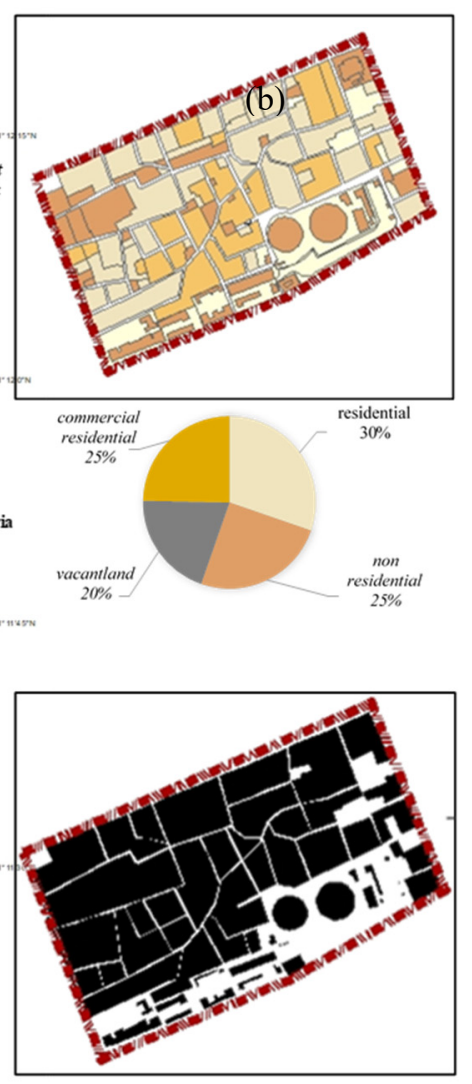

(c)

Figure 5: (a) Representing spatial analysis for Kom El Dikka neighborhood and surrounding context, with in the following radius 400, 800 and $1200 \mathrm{~m}$; (b) Representing percentages of land uses; and (c) Representing BUILT up area to open spaces within boundary of Kom El Dikka neighborhood. 
(mosque), commercial facilities ( shops), utilities (police station, water company )in addition to the residential use, and a high percentage of mixed commercial residential use this means that the basic needs of the residents are fulfilled with in a walking distance, according to the questionnaire, the results of the domain of pedestrian in Kom El Dikka were moderate (57.1\%) to low (28.6\%). Also, Kom El Dikka has an 75\% in the researchers' observation of the neighborhood's physical attributes.. but within $1 / 4$ mile there is lack of open spaces, only one newly developed park adjacent to the southern edge of Kom el Dikka and there is Also Alexandria Main Sports stadium. Within $1 / 2$ mile radius there is another two main parks; El Shalaet Park and Misr station parks and a Greek Roman theatre (it is Archaeological site). Analysing the $3 / 4$ mile the residents can reach mixed uses and residential uses. The spatial analysis shows that the neighborhood suffers from lack of open spaces within its boundaries, which is considered insufficient to the residents because of the neglection of the value of this historical place. However, the residents tried to participate in the protection of their neighborhood and did an attempt to increase the percentage of green areas, so that percentage of built up to open spaces is $80 \%$ to $20 \%$ with is and theses $20 \%$ are left vacant and some of them are privately owned, so the residents suffers from high percentage of built up area. These means that the percentage of open spaces and their quality and also shops were significantly and positively associated with sense of community.

\section{RECOMMENDATIONS}

Based on the research observation, the survey results, the resident's comments, and the statistical analysis, the authors identified the current situation. Then, they proposed some recommendations about enhancing and protecting the physical attributes to increase the sense of community in each neighborhood, as shown in Table 2.

Table 2: The researchers' recommendations. (Source: Authors.)

\begin{tabular}{|l|l|}
\hline Neighborhood & Recommendations \\
\hline Kafr Abdo & $\begin{array}{l}\text { 1. The establishment of civil associations to protect the neighborhood's } \\
\text { local character and action should be taken from residents to protect their } \\
\text { community and make decisions about their neighborhood. } \\
\text { 2. The presence of strict laws prevents the destruction of historical } \\
\text { buildings. } \\
\text { 3. The presence of a good public transportation network to reinforce their } \\
\text { common significance and foster a shared sense of place. }\end{array}$ \\
\hline \multirow{3}{*}{ Kom El Dikka } & $\begin{array}{l}\text { 1. The decisions makers should encourage empowerment and public } \\
\text { participation in decision-making. } \\
\text { 2. The financial support for Kom El Dikka Development Association. } \\
\text { 3. The studies on this neighborhood should be applicable, and the } \\
\text { government should stop the exploitation of Kom El Dikka from some fake } \\
\text { associations. } \\
\text { 4. The maintenance of this historical place. }\end{array}$ \\
\hline Sidy Bishr and \\
$\begin{array}{l}\text { El Seyouf } \\
\text { Kibly }\end{array}$ & $\begin{array}{l}\text { 2. Buildings in the same place should respect the concept of harmony and } \\
\text { people plan to execute within them. This highlights the need for } \\
\text { participative planning to identify potential users" needs, preferences, and } \\
\text { intentions. } \\
\text { 3. The maintenance of streets and services and the presence of a good } \\
\text { streetscape. }\end{array}$ \\
\hline
\end{tabular}




\section{CONCLUSION}

This research attempts to study the impact of the built environment on the sense of community and some variables related to the community's social experiences. Also, it aims at investigating the local residents' activities and their perception of the built environment, and their sense of community using community mapping. The sense of community was influenced by monthly income, age, and the majority of the built environment's physical attributes. The significance of the sense of community domains in descending order is community attachment and identity, social interaction, and pedestrian. Furthermore, this study attempts to analyze the spatial pattern of neighborhoods and how it affects the sense of community; from the analysis, it was obvious that the public spaces within the neighborhood had the most significant value. It is more effective than the public spaces in the surroundings. This is detected in Kafr Abdo, with a higher sense of community than Kom El Dikka. Also, the quality of public spaces and services provided in the neighborhood to the residents. In Kafr Abdo, the variety of shops and services they provide is totally different from that existing in Kom El Dikka. Moreover, the non-residential uses that vary is significant to the sense of community of locals. The most significant is the educational facilities, as in Kafr Abdo for instances, the percentage of educational facilities that range from a variety of nurseries and schools provide sufficient fulfillment for the residents, this is not fulfilled in Kom el Dikka neighborhood, in Kafr Abdo represent 32\% of total non-residential uses, while in Kom El Dikka 11\%. Followed by the shops that allow the gathering, in kafr Abdo are much higher than in Kom El Dikka $40 \%$ to $10 \%$. Finally, the police station that provides a sense of safety and security to neighborhood and Kafr Abdo is higher than in Kom El Dikka. Both neighborhood can provide their daily needs within walking distance as proved by the spatial analysis, but the quality of streets is better in Kafr Abdo than in Kom El Dikka, and all the aspects related to walkability as an aesthetic factor, the pavement width, street width is much better in Kafr Abdo than in Kom el Dikka. Therefore, it is highly important to provide a good quality of public spaces, various mixed uses, and commercial shops at the ground level, increasing social aspects and gathering points, safety, and security. Using the spatial analysis with the survey is very important as each one highlights important facts that need to be linked together for better improvement for the sense of community.

\section{ACKNOWLEDGEMENTS}

This research did not receive any specific grant from funding agencies in the public, commercial, or not-for-profit sectors.

\section{REFERENCES}

[1] U.S. EPA (EPA 842-B-01-003), Office of Water, Community Culture and the Environment: A Guide to Understanding a Sense of Place, Washington, DC, 2002.

[2] Chavis, D.M. \& Wandersman A., Sense of community in the urban environment: A catalyst for participation and community development. A Quarter Century of Community Psychology, eds T.A. Revenson et al., Springer: Boston, MA, 2002. DOI: 10.1007/978-1-4419-8646-7_14.

[3] Chipuer, H. \& Pretty, G., A review of the sense of community index: current issues, factor structure, reliability, and further development. Journal of Community Psychology, 27, pp. 643-658, 1999.

[4] Schweitzer, J., A description of sense of community in Lansing neighbourhoods' project. Presented at the "Defining Community, Reinforcing Society" Conference, University of Michigan, 1996. 
[5] CAPMAS, Statistical Yearbook, Central Agency for Public Mobilization and Statistics: Cairo, 2013.

[6] UNDP, State of the built environment and housing indicators of seven Egyptian cities, Cairo, Egypt: Comprehensive report, 2010.

[7] Chavis, D., Hogge, J., McMillan, D. \& Wandersman, A., Sense of community through Brunswik's lens: A first look. Journal of Community Psychology, 14, pp. 24-40, 1986.

[8] Farahani, L.M. \& Lozanovska, M., A framework for exploring the sense of community and social life in residential environments. Archnet-IJAR, 8(3), pp. 223-237, 2014.

[9] Kim, J. \& Kaplan, R., Physical and psychological factors in sense of community: New urbanist Kentlands and nearby Orchard village. Environment and Behavior, 36(3), pp. 313-340, 2004.

[10] Wood, L., Frank, L.D. \& Giles-Corti, B., Sense of community and its relationship with walking and neighborhood design. Social Science \& Medicine, 70, pp. 1381-1390, 2010.

[11] Mannarini, T., Tartaglia, S., Fedi, A. \& Greganti, K., Image of neighborhood, self image and sense of community. Journal of Environmental Psychology, 26, pp. 202214, 2006.

[12] Talen, E., Measuring the public realm: A preliminary assessment of the link between public space and sense of community. Journal of Architectural and Planning Research, 17, pp. 344-360, 2000.

[13] Mullan, E., Do you think that your local area is a good place for young people to grow up? The effects of traffic and car parking on young people's views. Health and Place, 9, pp. 351-360, 2003.

[14] Giles-Corti, B. et al., Evaluation of the implementation of a state government community design policy aimed at increasing local walking: Design issues and baseline results from RESIDE, Perth western Australia. Preventive Medicine, 46, pp. 46-54, 2008.

[15] Promotion Foundation, Vick, J.W. \& Perkins, D.D., Building community: Comparing resident satisfaction, sense of community, and neighboring in a new urban and a suburban neighborhood. Back to the Future: New Urbanism and the Rise of Neotraditionalism in Urban Planning, University Press of America: Lanham, 2013. 